\title{
DIAGNOSIS OF FUELS WITH INFRARED SPECTROSCOPY UTILIZATION
}

\author{
Stefan Cornak \\ University of Defence in Brno, Czech Republic \\ stefan.cornak@unob.cz
}

\begin{abstract}
The quality indicators of fuels for combustion engines are in the Czech Republic being monitored by The Customs Administration of the Czech Republic and The Czech Trade Inspection Authority. Moreover, in filling stations like 'Benzina', these indicators are secured by the monitoring called 'The Seal of Quality', which is performed by the technicians from the SGS Czech Republic laboratories. The aim of the aforementioned precautions is not only to secure the quality indicators of the fuels, but also to prevent the environmental hazards and secure the economic and tax policy of the state. Despite this monitoring, the results from the preventive inspections are still showing a rather alarming number of filling stations that are showing operational and seasonal divergences in terms of fuel quality indicators. These unwanted divergences are mostly caused by the transport from the producer to the filling stations. For example, after switching between various types of fuels that are transported by a particular cistern or any other type of tank, the fuels might get contaminated from each other. The contamination might be caused on purpose, by 'enhancing' the fuel with other substances. For example, those with a different rate of taxation than a particular fuel. Such procedure leads to degraded quality indicators and there is a side effect of tax evasion, too. Currently, the monitoring of the fuels is conducted in a special laboratory. Therefore, the need for a suitable operational identification method arose. This paper presents the summary of the author's knowledge and expertise, gained in the area of identification and diagnosis of fuel quality indicators in combustion engines. Fuels for diesel engines have been evaluated. The original hypothesis of the author that the infrared spectra can be utilized not just for identification of the fuel but also for evaluation of the fuel quality indicators was successfully confirmed by the outcomes. Changes in fuel parameters are reflected in a variation of absorbance values and spectrum widths. The creation of infrared spectrum databases leads to a routine diagnosis of fuel in operational practise.
\end{abstract}

Keywords: diesel, petrol, FAME, infrared spectrometry.

\section{Introduction}

Modern combustion engine is being engineered for at least 160 years. Mainly due to ecological, economic and political reasons, to avoid dependency on oil [1], the effort to replace the cylinder combustion engines with a different propulsion unit is rising. The electric motor seems to be a promising prospective replacement [2]. For its full utilization in terms of transport machines and devices, several problems need to be solved. The main challenge is the supply of the sufficient amount of electric energy to the motor from the sources carried within the vehicle (accumulator batteries) or the energy generated within the vehicle (fuel cells), or the distribution of the energy by the contactless way. Due to the aforementioned reasons, the majority of designers focus on the hybrid technologies, which are combining the conventional combustion engine with the electric one. The partial conclusion from the stated facts is that the combustion engine is and will be a crucial part of the propulsion units in the present and in the future.

A very high number of fuel types can be utilized for these engines [3]. Up to now and possibly still in the future the dominant fuels will be two of the basic types - petrol and diesel. For successful utilization of the fuels, the sum of qualitative indicator requirements has to be met. The fuels of poor quality can have undesirable impact of an engine, e.g. reduce its lifespan, affect the operation of catalytic systems etc.

Therefore, the quality indicators are strictly controlled and every state has its own institution dedicated for this cause. In the Czech Republic the institution is called The Czech Trade Inspection Authority. The results of their inspections are showing that the fuels of insufficient or suspicious quality are present in the distribution network [4]. The most common issue is contamination of the fuel types designed for different weather (summer type with winter type which has more additives), or contamination of petrol with diesel and vice versa. Such contaminations can occur during the transportation to the distributor, mainly during switching between the transported fuels in the cisterns or tanks. The contaminations can happen on purpose, e.g. intentional mixing of the fuels for the purpose of tax evasion, or just self-enhancing of the fuels with the consumer [5]. 
In the countries of the European Union, the issues with the fuels are very similar. Based on the report of the fuel quality within the states of the EU, one of twenty samples is inconsistent in its properties with the dedicated standard. Such differences are very similar for Belgium, France, Germany, Slovakia and Latvia [6]. Therefore, the topic of diagnosis of fuels is important and needs further investigation.

The diagnosis methods for fuel quality indicators can be divided into three groups - sensory, standardized and instrumental [7]. The sensory methods are simple, sufficient for a driver or a mechanic. The evaluated properties are the sort and quality, based of the appearance, colour, smell, limpidity, foamness etc. The standardized methods are the analytical laboratory methods that are strictly set by the national standards. The diagnosis and evaluations of the fuel quality indicators are based on the measurement of the physico-chemical parameters. In case of diesel fuel, these parameters are set by the standard ČSN EN 590 [8]. For example, the flash point, amount of ash, amount of water, total volume of impurities, corrosive effect on copper, oxidational stability, volume of sulphur, lubricity at $60{ }^{\circ} \mathrm{C}$, cetane number, cetane index, density at $15^{\circ} \mathrm{C}$, viscosity at $40{ }^{\circ} \mathrm{C}$, temperature of the end of distillation and the amount of polycyclic aromatic hydrocarbons. In case of petrol fuel, the parameters are set by the standard ČSN EN 228 [9], for example: the octane number, steam pressure, density, distillation test (the evaporated amount at temperatures $70{ }^{\circ} \mathrm{C}, 100{ }^{\circ} \mathrm{C}, 150{ }^{\circ} \mathrm{C}$ and the temperature of the end of evaporation), characteristic analysis (the volume of olefins, aromates and benzene), and the volume of sulphur, oxygen and lead. The standardized methods require a special laboratory and specially educated personnel. The quality of these methods is quite high, nevertheless they are very complex and time consuming. For example, the analysis of diesel fuel according to the standard EN 590 in the dedicated laboratory can take up to several months. Therefore, for the operational needs these methods are inappropriate. They are sufficient in case of introducing a new fuel type, or for inspection of the quality indicators for the freshly produced batch of fuel. The instrumental methods are very expensive, but with the help of the special apparatus, they enable inspection of more parameters at once and detect the possible contamination with a different substance. The instrumental methods are often based on the principle of infrared spectrometry. Currently, the fuel quality indicators are monitored in special laboratories, with utilizations of special standardized methods [10-14]. However, operational practice lacks a simple identification and diagnosis method for fuel quality indicators. The presented paper deals with such a method.

\section{Material and methods}

In case of contemporary military vehicles, the preferred fuel, due to its flammability, is diesel fuel. Therefore, as the first step, the samples of few types of diesel were bought. The samples were designated for different weather conditions- B type as the summer diesel, D type as the autumn/spring diesel and $\mathrm{F}$ type as the winter diesel. The samples were stored in special storage boxes in the laboratory. The first measurement was conducted immediately after the samples were purchased, the second after three months and the last one after six months.

The analysis was conducted with utilization of the device IROX DIESEL- the analyzer of diesel fuels, equipped with the infrared spectrometer based on the Michelson type. The working principle of the device is based on measurement of the infrared absorption, defined by the Lamber-Beer law.

$$
I=I_{0} \cdot e^{-\varepsilon . c . l}
$$

where $I_{0}$-intensity of the input radiation;

$I$-intensity of the output radiation;

$\varepsilon_{0}-$ absorption coefficient;

$l$ - length of the absorption environment;

$c$ - concentration of the substance.

The working principle of the aforementioned device can be seen in Fig. 1. The ray from the source (1) is directed through the mirror (2) to the semi-permeable mirror (3). One ray is reflected by the fixed mirror (4) and the other ray is reflected by the moveable mirror (5). Both rays are put together again in the semi-permeable mirror (3) and then routed towards the measuring cuvette (6) and from there through the mirror to the detector (8). 
The result is the interferogram (dependence of the intensity of the incident radiation over time). With utilization of the Fourier transformations, the interferogram is converted into the spectrum. Based on the measured spectra, by application of the sufficient mathematical models, procedures and programs, the quality indicators of the diesel fuel are obtained. Before the measurements, the calibrations of the device were carried out. The calibration fluid was the $99+\%$ n-hexane. All of the measurements were taken twice, their evaluations were performed with the software dedicated to the device- IROX DIESEL MINIWIN 2.2.4.

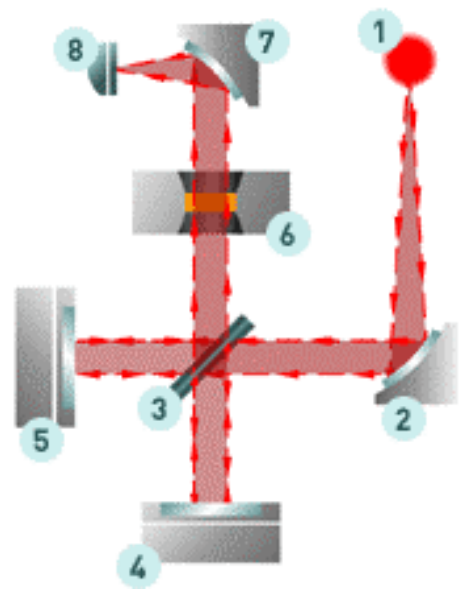

Fig. 1. Working principle of IROX DIESEL [15]: 1 - source; 2, 4, 7 - mirror; 3 - semi-permeable mirror; 5 - moveable mirror; 6 - cuvette; 8 - detector

\section{Results and discussion}

With utilization of the IROX DIESEL device, three samples of the diesel fuel were analysed- the aforementioned weather types B, D and F. The primal result was the spectrogram. Presented in Fig. 2 are the results for D type diesel, only one type of the result is presented due the scope of the paper. From the spectra the storage effect can be seen, manifested as the changed height and width of the pikes.

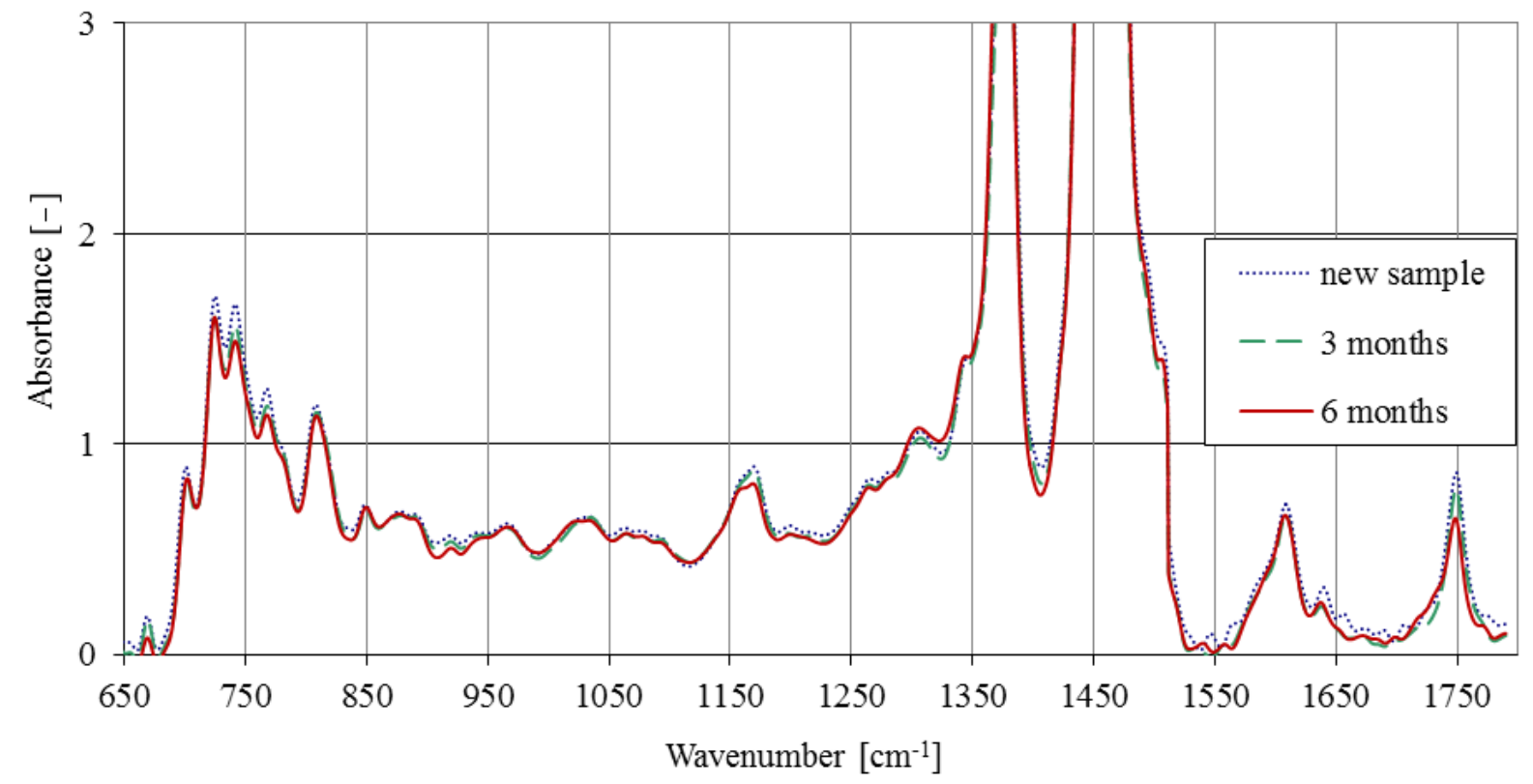

Fig. 2. Dependence of absorbance on wavelength of infrared spectrum for $D$ type diesel

Based on the measured spectra, with utilization of the special algorithm/software of the device, the chosen parameters were set. The summary results are presented in Table 1.There can be seen the storage effect, which is changing (degrading) all of the monitored physico-chemical parameters. The most alarming warning is the degradation of the cetane number below the value of 51 after the 
6 months. So, the diesel fuel stored in the tank should be consumed as soon as possible due to degradation of the fuel quality indicators caused by its storage. The diesel fuel quality indicators mainly changed by the various types of additives. These are added on purpose, e.g. the legislatively stated FAME additives.

Table 1

Summary results of diesel diagnosis with IROX DIESEL device

\begin{tabular}{|c|c|c|c|c|c|c|c|c|c|}
\hline \multirow{4}{*}{$\begin{array}{l}\text { Monitored } \\
\text { parameter* }\end{array}$} & \multicolumn{9}{|c|}{ Diesel types } \\
\hline & \multicolumn{3}{|c|}{ DIESEL - class B } & \multirow{2}{*}{\multicolumn{3}{|c|}{$\begin{array}{c}\text { DIESEL }- \text { class D } \\
\text { Storage time, months }\end{array}$}} & \multicolumn{3}{|c|}{ DIESEL - class F } \\
\hline & Stora & time, $n$ & nths & & & & Storag & time, $\mathrm{m}$ & nths \\
\hline & 0 & 3 & 6 & 0 & 3 & 6 & 0 & 3 & 6 \\
\hline 1 & 28.8 & 28.3 & 26.4 & 30.3 & 28.3 & 27.8 & 34.6 & 33.3 & 34.8 \\
\hline 2 & 5.0 & 5.0 & 4.8 & 2.8 & 5.0 & 2.5 & 4.5 & 3.1 & 5.9 \\
\hline 3 & 52.4 & 50.7 & 49.4 & 51.7 & 50.7 & 51.3 & 51.9 & 51.4 & 50.4 \\
\hline 4 & 49.0 & 48.7 & 45.8 & 49.4 & 48.7 & 46.4 & 51.0 & 50.9 & 51.0 \\
\hline 5 & 1609.0 & 856.0 & 792.0 & 1540.0 & 856.0 & 753.0 & 1045.0 & 621.0 & 818.0 \\
\hline 6 & 340.7 & 339.6 & 315.5 & 338.6 & 339.6 & 320 & 350.4 & 353.3 & 359.4 \\
\hline 7 & 634.0 & 362.1 & 333.8 & 362.3 & 362.1 & 338.8 & 375.0 & 377.6 & 382.7 \\
\hline 8 & 1.9 & 1.5 & 0.1 & 2.9 & 1.5 & 0.8 & 5.0 & 4.9 & 4.7 \\
\hline 9 & 11.4 & 9.0 & 0.6 & 17.4 & 9.0 & 4.8 & 30.0 & 27.4 & 27.2 \\
\hline 10 & 0.834 & 0.836 & 0.838 & 0.832 & 0.836 & 0.836 & 0.832 & 0.834 & 0.835 \\
\hline 11 & 0.4 & 0.2 & 0.0 & 1.7 & 0.2 & 0.0 & 3.8 & 3.6 & 6 \\
\hline
\end{tabular}

* Monitored parameters: 1 - overall content of aromatic compounds [ \% vol.], 2 - multi-kernel (PN) aromatic compounds [ \% vol.], 3 - cetane number, 4 - cetane index, 5 - additive for cetane number improvement $[\mathrm{ppm}], 6$ - distillation characters $(\mathrm{T} 90)\left[{ }^{\circ} \mathrm{C}\right], 7$ - distillation characters (T95) $\left[{ }^{\circ} \mathrm{C}\right], 8$ - content of ethyl-ester [ \% vol.], 9 - content of methyl-ester [ $\%$ vol.], 10 - consistence $\left[\mathrm{g} \cdot \mathrm{cm}^{-3}\right], 11$ - FAME [ \% vol.]

Others can enhance the chosen parameters like the cetane number etc. For the purpose of tax evasion, diesel can be mixed with other substances, which have a similar density and viscosity, but are cheaper and have a smaller tax charge. This process is called adulteration of the diesel fuel, the most common substances used for this purpose are the light industrial lubricating, transformer or mold oils.

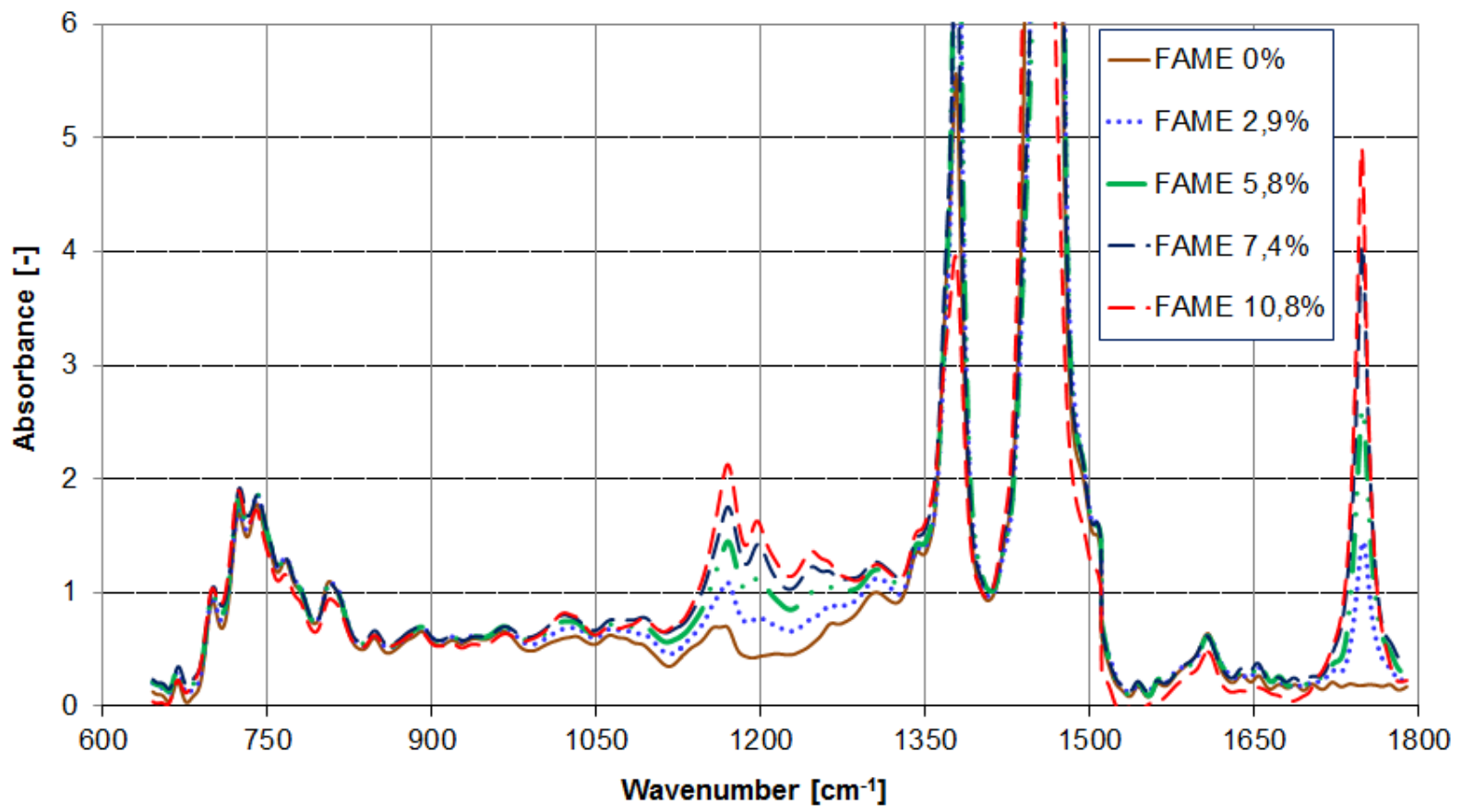

Fig. 3. Overall dependence of absorbance on wavelength for different volume of FAME 
Unintentional additives, the so called contamination, can be caused by poor cleaning of the cistern or tank that transported petrol fuel before diesel. With utilization of the infrared spectrometry, even the aforementioned contamination can be analysed. The legislative law states that the additive for diesel fuel is the specified volume of the FAME. For further investigation of the FAME share in diesel, the samples of the mixture of diesel and bio diesel (FAME) were created. The share of FAME in the samples was the $0 \%, 2,9 \%, 5,8 \%, 7,5 \%$ and $10,8 \%$. The summary results are presented in Fig. 3, where the typical peaks for the diesel around the wavenumbers $1370 \mathrm{~cm}^{-1}$ and $1460 \mathrm{~cm}^{-1}$ can be seen. With the rising share of the FAME- Fig. 4, the peaks are being changed around the wavenumbers $1170 \mathrm{~cm}^{-1}$ and mainly $1748 \mathrm{~cm}^{-1}$.

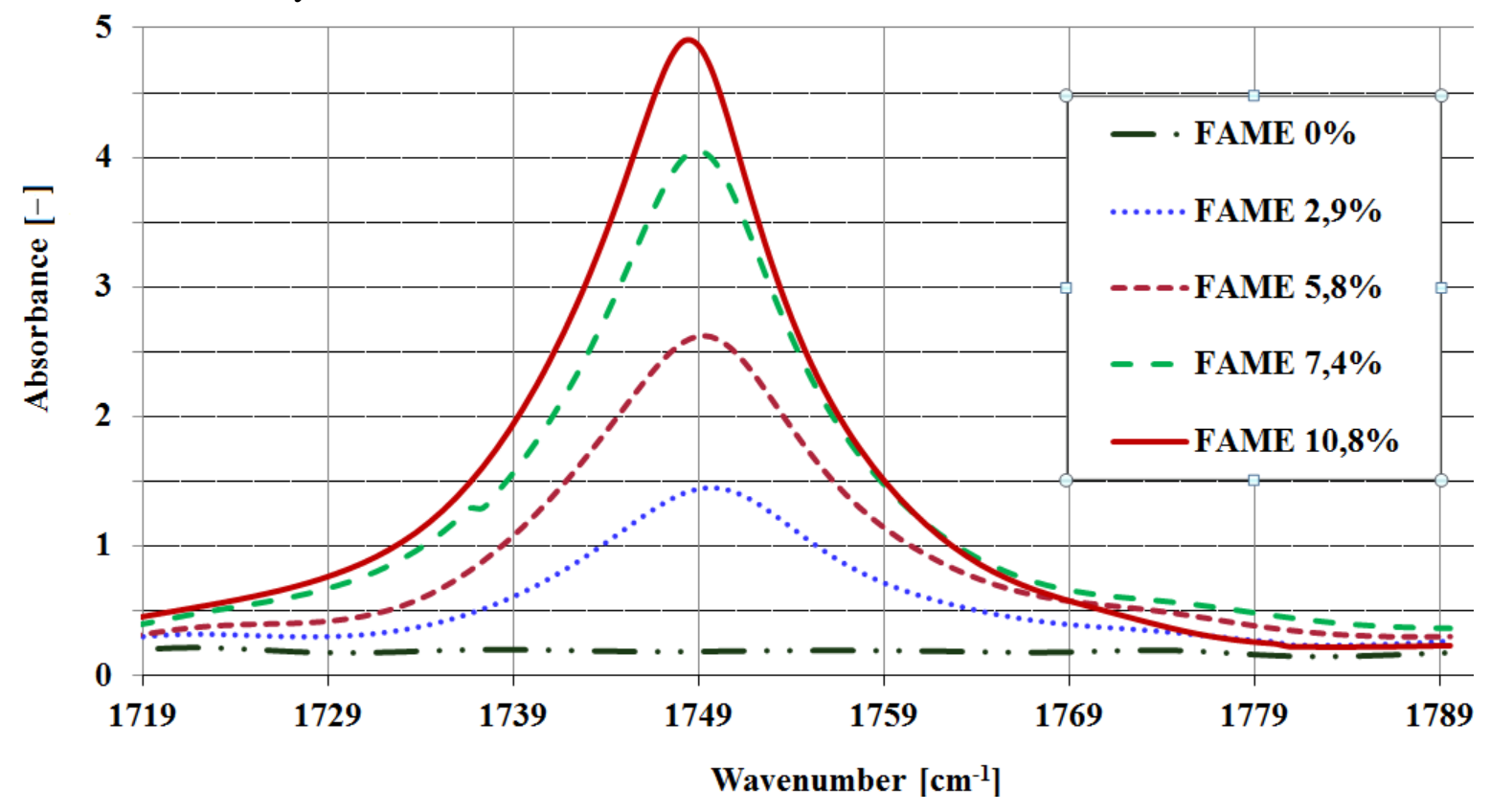

Fig. 4. Dependence of absorbance on wavelength with various volumes of FAME

From Fig. 4 it is obvious that with the zero share of FAME in the diesel, the absorbance is very close to the value of 0 . With the volume of FAME 2,9 \% the absorbance is 1,43, for FAME 5.8 it is 2,61 , for FAME $7.4 \%$ it is 4,12 and for the volume of FAME $10,8 \%$ the absorbance is 4.91 . The result from the aforementioned values is that the spectra (the absorbance values for the wave number around $1748 \mathrm{~cm}^{-1}$ ) can be utilized as the standard or reference for evaluations of the FAME share in diesel fuel. As the illustration, in Fig. 5 are presented the spectra of the two purchased samples of the diesel fuel from the distributional net.

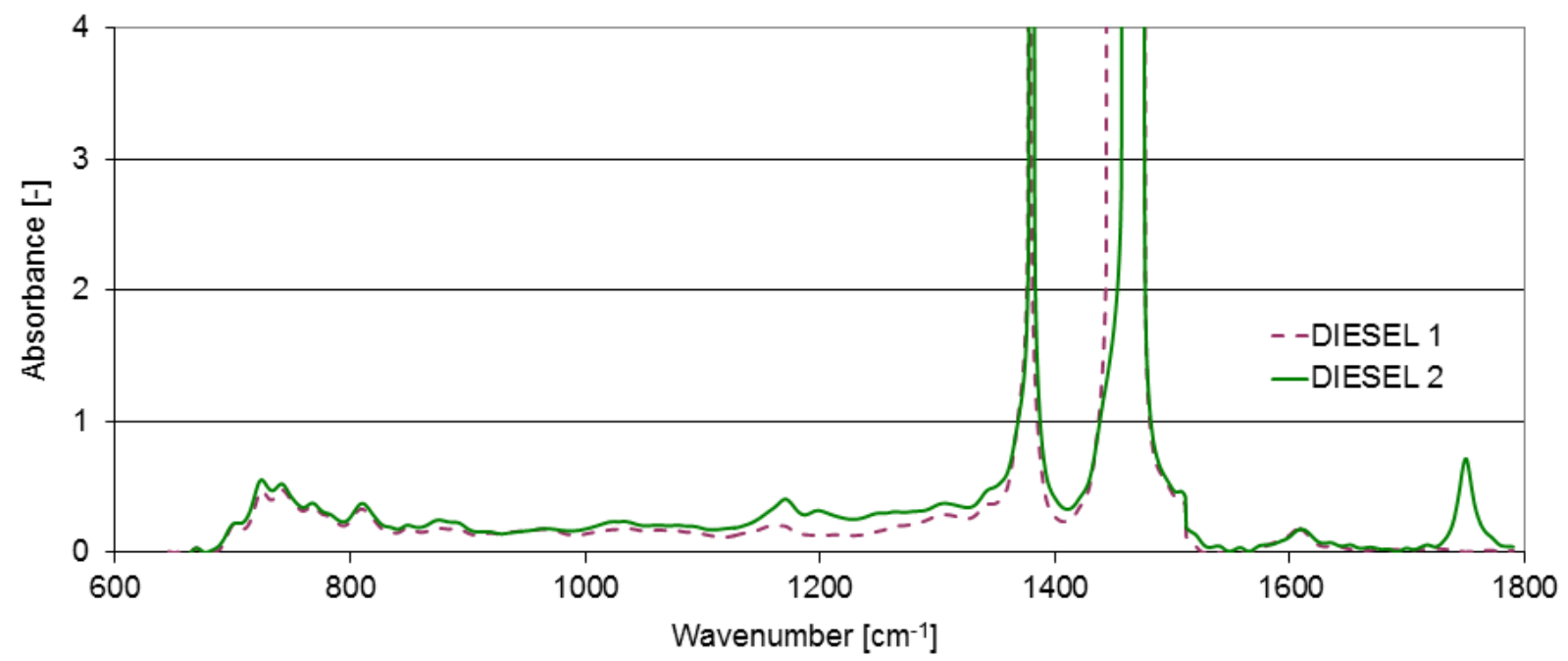

Fig. 5. Dependency of absorbance on wavelength of infrared spectra of diesel samples 
The result from Fig. 5 is clear, around the wavenumber of $1748 \mathrm{~cm}^{-1}$ for the sample DIESEL 1 the value of absorbance is close to 0 (the sample is without FAME), for the sample DIESEL 2 the value of absorbance is 0.69 (the sample has a shade of FAME of $1.4 \%$ ). According to the distributor, the DIESEL 2 is supposed to be without any share of FAME. In a similar way, the database of other fuels - diesel, petrol, light fuel oil, alcohol and paraffin was created. Their contamination was mainly caused by their transport in the cisterns or tanks, where previously other fuel type was transported. Due to the options and the range of this paper, all of the results are not published, but they are available from the author of this article.

\section{Conclusions}

With utilization of the IROX DIESEL device the samples of diesel with various shares of FAME were evaluated. The results have shown that with infrared spectra identification of the fuel types is possible, along with its quality indicators. Contamination with a different substance will manifest through the change of the values of absorbance and the width of the spectrum. The creation of such a database of infrared spectra leads to the routine diagnosis of fuels in operational practice.

\section{Acknowledgement}

The presented paper has been prepared with the support of the Ministry of Defence of the Czech Republic, Partial Project for Institutional Development, K-202, Department of Combat and Special Vehicles, University of Defence, Brno.

\section{References}

[1] Difiglio C. Oil, economic growth and strategic petroleum stocks. Energy strategy reviews, Volume 5, December 2014, pp. 48-58.

[2] Scaffidi C. Electrically Assisted International Combustion Engines: A Comparative Analysis. International journal of automotive technology. Volume 19, Issues 6, December 2018, pp. 10911101.

[3] Matějovský V. Vehicle fuels. Grada 2004, ISBN 80-247-0350-5. (In Czech).

[4] The results of the quality control of the fuels in year 2018. ČOI, Prague 2019. (In Czech). https://www.coi.cz/vysledky-kontrol-jakosti-pohonnych-hmot-v-roce-2018/, staženo 7.3.2019

[5] Mužiková Z., Šimáček P. Application of GC-FID in Monitoring Composition of Motor Fuels. In: Chemické listy, 2014, č. 108, pp. 1067-1072. ISSN 0009-2770. (In Czech).

[6] EEA, 2018, Fuel quality in the EU in 2016 (doi: 10.2800/224432).

[7] Čorňák Š. Identification of operating fluids with fingerprint method utilization. In: 17th International Scientific Conference Engineering for Rural Development. Jelgava: Latvia University of Agriculture, 2018, pp. 2048-2053. ISSN 1691-5976.

[8] Motor fuels - Technical requirements and test methodology ČSN EN 590 (In Czech).

[9] Motor fuels - Technical requirements and test methodology ČSN EN 228 (In Czech).

[10] Káňa J., Chudoba J., Šimáček P., Pospíšil M. Determination of Trace Concentrations of Biodiesel in Aviation Kerosin. Chemické listy, 2013, č. 106, pp. 665-671. ISSN 0009-2770. (In Czech).

[11] Caneca, A. R., Pimentel, M. F., Galvao, R. K. H. et. al. Assessment of infrared spectroscopy and multivariate techniques for monitoring the service condition of diesel-engine lubricating oils. Talanta, 70(2), 2006, pp. 344-352.

[12] Polikarpov E et all. Critical fuel property evaluation for potential gasoline and diesel biofuel blendstocks with low sample volume availability. In: Fuel. Volume 238, pp. 26-33, DOI: 10.1016/j.fuel.2018.09.129.

[13] Ben Amara A., Dauphin R., Babiker H., et al. Revisitingdiesel fuel formulation from Petroleum light and middle refinery streams based on optimized engine behavior, FUEL vol 174, 2016, pp. 63-75.

[14] Khaskheli, AA, et all: Performance Evaluation of Locally-Produced Waste Cooking Oil Biodiesel with Conventional Diesel Flue. In: Engineering Technology \& Applied Science Research, Volume 8, Issue 6, pp. 3521-3524.

[15] IROX DIESEL. Portable FTIR fuel analysis. Grabner instruments ${ }^{\mathrm{TM}}$, Vienna 2006. 